\title{
ARTICLE \\ Mice with reduced DAT levels recreate seasonal-induced switching between states in bipolar disorder
}

\author{
Jared W. Young ${ }^{1,2}$, Zackary A. Cope ${ }^{1}$, Benedetto Romoli ${ }^{1}$, Esther Schrurs ${ }^{1,3}$, Aniek Joosen ${ }^{1,3}$, Jordy van Enkhuizen ${ }^{1}$,
} Richard F. Sharp ${ }^{1}$ and Davide Dulcis ${ }^{1}$

Developing novel therapeutics for bipolar disorder (BD) has been hampered by limited mechanistic knowledge how sufferers switch between mania and depression-how the same brain can switch between extreme states-described as the "holy grail" of $B D$ research. Strong evidence implicates seasonally-induced switching between states, with mania associated with summer-onset, depression with winter-onset. Determining mechanisms of and sensitivity to such switching is required. C57BL/6J and dopamine transporter hypomorphic (DAT-HY 50\% expression) mice performed a battery of psychiatry-relevant behavioral tasks following 2week housing in chambers under seasonally relevant photoperiod extremes. Summer-like and winter-like photoperiod exposure induced mania-relevant and depression-relevant behaviors respectively in mice. This behavioral switch paralleled neurotransmitter switching from dopamine to somatostatin in hypothalamic neurons (receiving direct input from the photoperiod-processing center, the suprachiasmatic nucleus). Mice with reduced DAT expression exhibited hypersensitivity to these summer-like and winter-like photoperiods, including more extreme mania-relevant (including reward sensitivity during reinforcement learning), and depressionrelevant (including punishment-sensitivity and loss-sensitivity during reinforcement learning) behaviors. DAT mRNA levels switched in wildtype littermate mice across photoperiods, an effect not replicated in DAT hypomorphic mice. This inability to adjust DAT levels to match photoperiod-induced neurotransmitter switching as a homeostatic control likely contributes to the susceptibility of DAT hypormophic mice to these switching photoperiods. These data reveal the potential contribution of photoperiod-induced neuroplasticity within an identified circuit of the hypothalamus, linked with reduced DAT function, underlying switching between states in BD. Further investigations of the circuit will likely identify novel therapeutic targets to block switching between states.

Neuropsychopharmacology (2018) 43:1721-1731; https://doi.org/10.1038/s41386-018-0031-y

\section{INTRODUCTION}

Bipolar disorder (BD) is a lifelong disease affecting $2-5 \%$ of the worldwide population from an early age. In 1998, the lifetime costs to US taxpayers for persons with BD amounted to $\$ 24$ billion, up to $\$ 624,785$ per person from attempts to treat people plus lost productivity [1]. BD is a unique disorder transcending domains of function, characterized by polar opposite behaviors switching between depression (behavioral despair, punishment hypersensitivity), and mania (risk-preference, reward hypersensitivity), within each patient. Hence, generating model animals of BD has proven difficult. Delineating the mechanism of the switch is 'the holy grail for research in $\mathrm{BD}^{\prime}$ [2], and while separate models of each exist [3, 4], as yet no in vivo animal model of this switching have been developed. This lack of knowledge is in-part why no approved treatments have been developed with $\mathrm{BD}$ as the target, but identified serendipitously [5].

Research to-date has provided insights into the underlying neurochemistry during periods of depression and mania, identifying altered cholinergic-mediated and dopaminergic-mediated function among the factors that influence these two states respectively [6]. Delineating how such neurochemistry imbalance alters at the cellular level in an individual remains key however, for maintenance treatment in BD ([2]; Young et al., 2015). Although numerous triggers can drive a $\mathrm{BD}$ sufferer into a manic or depressed state, they drive one episode or the other with little-tono overlap (Young et al., 2015). One dual-state trigger exists however, that is changing seasons (referred to as seasonality in BD), first recognized by Hippocrates over 2000 years ago (Young et al., 2015). Specifically, mania episodes occur in spring/summer, while depression episodes are prevalent in fall/winter [7-13], supported in a meta-analysis [14]. Although not seen in every BD patient, potentially reflecting subtypes of $\mathrm{BD}$ or because of the abundance of artificial lighting, seasonality has been observed historically and affects other disorders ([15]; Young et al., 2015). Certainly, seasonal affective disorder is common wherein people enter a depressed episode as the photoperiod (day) length shortens [16-18]. Two efficacious behavioral therapies for BD sufferers, bright light exposure (phototherapy) [19-22] and social rhythm therapy [23, 24], both seek to maintain a fixed photoperiod/activity lengths. How such changing photoperiods could drive both neurochemical and behavioral profiles (of depression and mania) in adults but underlying mechanisms have remained unclear until recently.

Photoperiod-dependent neurotransmitter respecification was noted where light exposure dynamically regulated dopaminergic neurons located in the frog hypothalamus [25]. Rodent studies

\footnotetext{
${ }^{1}$ Department of Psychiatry, University of California San Diego, 9500 Gilman Drive MC 0804, La Jolla, CA 92093-0804, USA; ${ }^{2}$ Research Service, VA San Diego Healthcare System, San Diego, CA, USA and ${ }^{3}$ Division of Pharmacology, Utrecht Institute for Pharmaceutical Sciences, Utrecht University, Utrecht, Netherlands Correspondence: Jared W. Young (jaredyoung@ucsd.edu) or Davide Dulcis (ddulcis@ucsd.edu)
} 
followed, delineating that neurons in light-processing nuclei, such as the para-ventricular and peri-ventricular nuclei of the hypothalamus in nocturnal animals switch neurotransmitter phenotype in a photoperiod-dependent manner. In winter-like (short-active; SA) photoperiods, $19 \mathrm{~h} / 5 \mathrm{~h}$ Light (L):Dark(D), these neurons express somatostatin (SST), subsequently affecting transmission of corticotrophin-releasing factor (CRF). In contrast, summer-like (long-active; LA) photoperiod (5L:19D) SST-expressing neurons respecify to express the dopamine synthesizing enzyme tyrosine hydroxylase (TH) [26]. This neurochemical switch in neurotransmitter expression was more recently confirmed in humans that died in summer (LA) vs. winter (SA) [27], mirroring effects observed in nocturnal animals. Unlike human post-mortem studies, rat studies identified mania-relevant and depressionrelevant behaviors resulting from these LA-like vs. SA-like photoperiods conditions respectively [26]. Healthy humans may also exhibit an altered mood state in summer vs. winter photoperiod conditions, but not as extreme as mania or depression. Hence, it remains likely that BD sufferers possess a susceptibility to such photoperiod-induced neurotransmitter switching. Given the high heritability of BD $[\sim 80 \%$ [28]], this susceptibility is likely of genetic origin.

Dopamine transporter (DAT) polymorphisms have been associated with BD [29,30], likely reducing cell surface migration [31] down-regulating its functional expression. Reduced functional DAT expression was confirmed in unmedicated euthymic BD patients using positron emission tomography studies observing 20-30\% lower DAT expression levels compared to healthy participants [32]. Reduced DAT expression may convey a susceptibility to switching between states by limiting the capability of homeostatic control mechanisms to adjust to changing dopamine expression. Hence, the functional consequences of reduced hypothalamic dopamine-expressing (and releasing) neurons of SA photoperiod-treated rodents would be exacerbated by the loss of function of DAT, being the key transporter mediating dopamine re-uptake from the synaptic cleft. Alternatively, BD sufferers also exhibit altered circadian rhythms compared to healthy participants, and mice with a deletion of exon 19 in the circadian locomotor output cycles kaput (CLOCK) gene (Clock $\Delta 19$ mice) exhibit some mania- and depressionrelevant behaviors that can be attenuated with lithium treatment $[33,34]$. Interestingly DAT KD mice also exhibit altered circadian rhythms [35]. Given that social rhythm therapy aids the stability circadian rhythm of BD sufferers, both genes may contribute to susceptibility to switching between states in BD.

Here, we hypothesized that DAT hypomorphic (HY) mice (with reduced $\sim 50 \%$ DAT expression) and Clock $\Delta 19$ mutant mice would exhibit a susceptibility to photoperiod-induced changes in neurotransmitter and behavior profiles that are consistent with mania and depression in BD.

\section{Materials and methods}

Animals. Several cohorts of mice were used including male C57BL/6 J mice $(n=33)$, male DAT HY $(n=30 ; 76)$, and wildtype (WT; $n=19,76)$, littermate mice bred in-house from WT and HY breeding pairs [36], and male CLOCK $\Delta 19$ mutant mice on a C57BL/ $6 \mathrm{~J}$ background bred from heterozygous breeding pairs as previously described [37-39]. The DAT HY mice were heterozygous for the knockdown gene generated by Zhuang et al. [36], expressing approximately $50 \%$ of DAT vs. WT mice, in contrast with $0 \%$ expression of DAT knockout mice. Training and testing began at 3 months old $(20-40 \mathrm{~g})$. All mice were group housed (maximum four per cage) and maintained in climate-controlled photoperiod chambers. These photoperiod chambers were set to one of three reversed photoperiod conditions, a SA photoperiod (day/night cycle, lights on at $1500 \mathrm{~h}$, off at $1000 \mathrm{~h}$ ), a normal-active (NA) photoperiod (lights on at $2200 \mathrm{~h}$, off at $1000 \mathrm{~h}$ ), or a LA photoperiod (lights on at 0500 , off at $1000 \mathrm{~h}$ ). Mice were maintained in these conditions for at least 2 weeks prior to testing. These chambers were individually ventilated and illuminated to 130 lumens, measured in the center of the chamber, by 3 horizontal, programmable white LED strips equally spaced vertically on each side wall. These chambers were maintained in a dark room throughout habituation and testing, to avoid light spillage during dark periods. For each experiment, these mice were tested during their shared 5-hour dark phase. Food (Harlan Teklad, Madison, WI) and water were available ad libitum except during training and testing. In food reinforced experiments, food was restricted to maintain mice at $\sim 85 \%$ full body weight as is common [40-42]. All mice were maintained in an animal facility that meets all federal and state requirements for animal care and was approved by the American Association for Accreditation of Laboratory Animal Care. All procedures were approved by the University of California San Diego Animal Care and Use Committee. Experimental details are described in brief below but for details see Supplemental Materials.

\section{5-choice apparatus and behavioral testing}

Sound-insulated five-hole operant chambers (Med Associates, Inc., St. Albans, VT) were used as described previously. In brief, each chamber contained a house light, fan, array of five apertures and a liquid delivery magazine (Lafayette Instruments, Lafayette, IN) which contained a well for liquid reinforcement (strawberry Nesquik ${ }^{\circledast}$ plus non-fat milk, $30 \mu \mathrm{L}$ ), delivered by a peristaltic pump (Lafayette Instruments, Lafayette, IN). Stimuli were recorded and managed by a SmartCtrl Package 8-In/16-Out with additional interfacing by MED-PC for Windows (Med Associates, Inc.) using custom programming. For details see Supplemental Materials.

\section{Probabilistic learning test (PLT)}

Mice were trained to respond in apertures for food rewards as previously detailed ([43, 44]; Cope et al., 2017; [42]). In brief, two apertures were illuminated (one target and one non-target) for 10 $\mathrm{s}$, with responses leading to reward or punishment at a $80 / 20$ ratio, opposite for non-target stimuli. Performance was assessed over 80 trials or $60 \mathrm{~min}$, measuring accuracy, reward responsiveness (latency to collect rewards and win-stay), and punish sensitivity (perseverative punish responses and lose-shift).

\section{Progressive ratio breakpoint study (PRBS)}

Two days following PLT, mice performed the PRBS, as described $[45,46]$. In short, mice poked for a reward with increased response-requirements on a progressive ratio. Motivation was measured as breakpoint (last ratio completed), and reward sensitivity (latency for reward retrieval).

\section{Elevated plus maze (EPM)}

The EPM was originally designed to assess fear/avoidance, a form of risk assessment. The EPM apparatus consisted of two elevated perpendicularly oriented aluminum runways painted white intersecting in the center. One runway was enclosed by a melamine barrier covered by black card stock (closed arm), with the other not enclosed (open arm). The maze was isolated from the experimenter using portable partitions. All testing took place under ambient fluorescent room lighting during the animals' active period. Mice were placed into the center region facing the same closed arm, with open, closed arm, and center entries hand scored with ODLog (Macropod Software, Yarraville, Victoria, Australia), defined by the location of the animal's forepaws and head in the maze over $5 \mathrm{~min}$.

Forced swim test (FST)

The FST was originally designed to assess despair-related behavior. Mice were placed in a clear glass beaker with a diameter of $15 \mathrm{~cm}$, a height of $24 \mathrm{~cm}$, and $15 \mathrm{~cm}$ of water at $25^{\circ} \mathrm{C}$, with immobility duration scored for $6 \mathrm{~min}$. Immobility was defined as 
A

\section{Forced Swim Test}

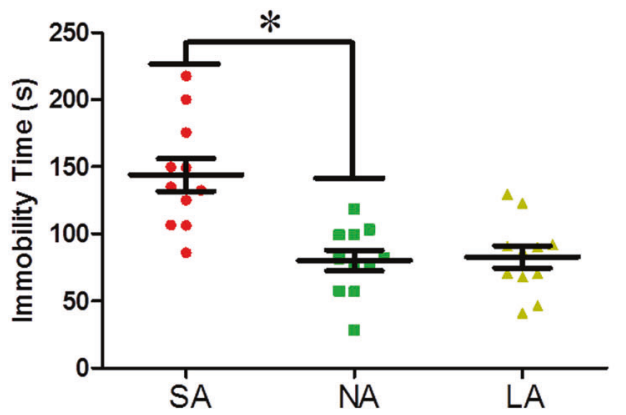

C

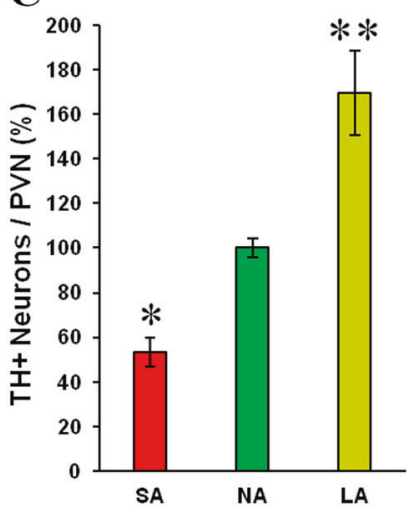

B

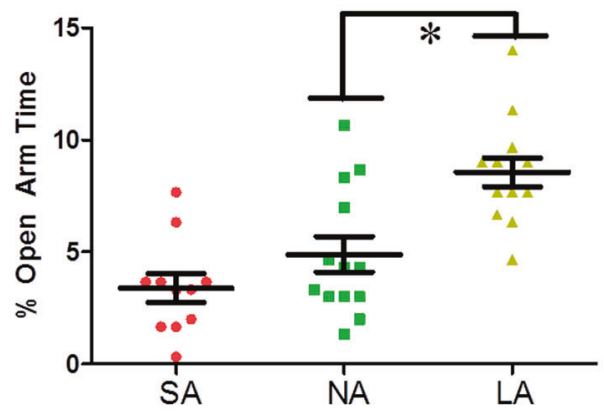

E
D

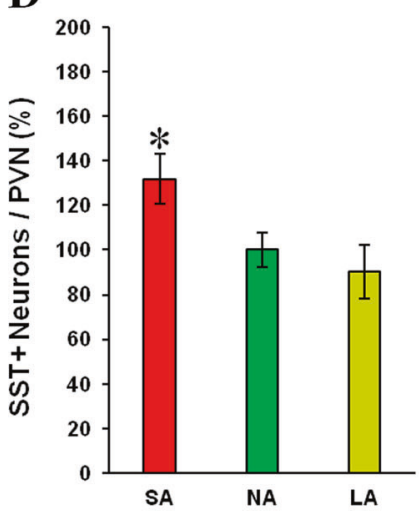

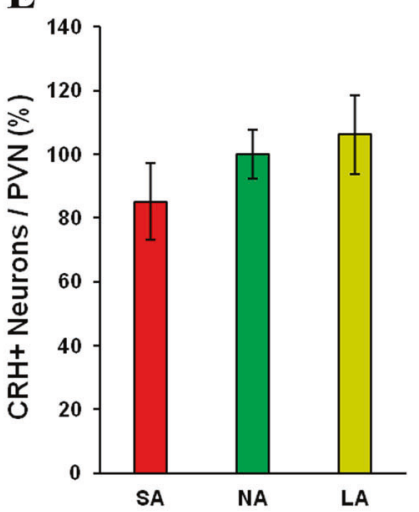

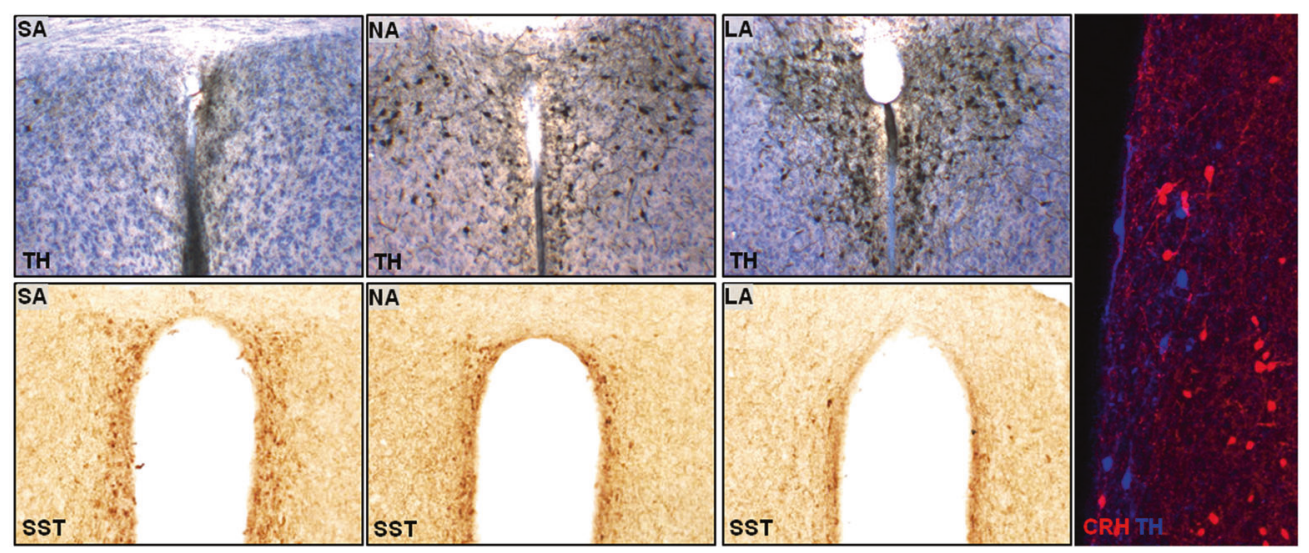

Fig. 1 Winter- and summer-like photoperiods drive depression- and mania-relevant behaviors and neurochemistry. C57BL/6J mice are awake during dark photoperiods and so were housed in short-active (SA; 19L:5D), vs. normal active (NA; 12L:12D), vs. long-active (LA; 19D:5L) photoperiod conditions for 2 weeks (schematic on top) prior to testing. SA-housed mice exhibited depression-relevant behavior relative to controls (NA) as indicated by increased immobility (despair-like behavior), in the forced swim test (FST; a). In contrast, mice housed in summerlike (LA; 5L:19D) photoperiod conditions for 2 weeks exhibited mania-like behavior as indicated by increased open arm entries (risk-prone behavior) in the elevated plus maze (EPM; b). This change in behavior was accompanied by photoperiod-induced regulation of the number of $\mathrm{TH}+(\mathbf{c})$, and SST $+(\mathbf{d})$, neurons in the paraventricular nucleus (PVN) of these mice without altering the number of $\mathrm{CRH}+$ neurons (e), compared to NA controls. Representative images of TH and SST immunoreactivity within the PVN from each photoperiod condition are presented. Data presented as individual data points plus mean \pm S.E.M. Asterisk denotes $p<0.05,{ }^{* *} p<0.01$ compared to NA controls

no movement except minor corrections required to keep afloat. After testing, the animal was dried and returned to an unoccupied cage with a heating pad before returning to its home cage.

Quantification of TH+ and SST+ neurons in the paraventricular nucleus

Mice for each genotype and experimental group (Supplementary Table) were intracardially perfused and their brains sectioned (30 $\mathrm{mm}$-thick sections) for DAB immunohistochemistry (IHC) processing. Incubation with antibodies against $\mathrm{TH}$ and SST markers (mouse monoclonal anti-TH, 1:500, Millipore; rabbit anti-
SST, Chemicon 1:300) was followed by Giemsa counterstaining. Stained tissue was imaged with a slide scanner. Stereological quantification of $\mathrm{TH}+$ and SST+ neurons in the PVN of the hypothalamus was performed blind with the Stereologer software. For each animal, we quantified eight horizontal sections through the hypothalamus to include the paraventricular and the periventricular nuclei. The criteria of ROI selection was standardized to include the PVN of the hypothalamus based on Paxinos Mouse Brain Atlas, starting at Bregma $-0.59 \mathrm{~mm}$ (AP). The quantification data is shown as the average of the total number of neurons/nucleus/animal. 

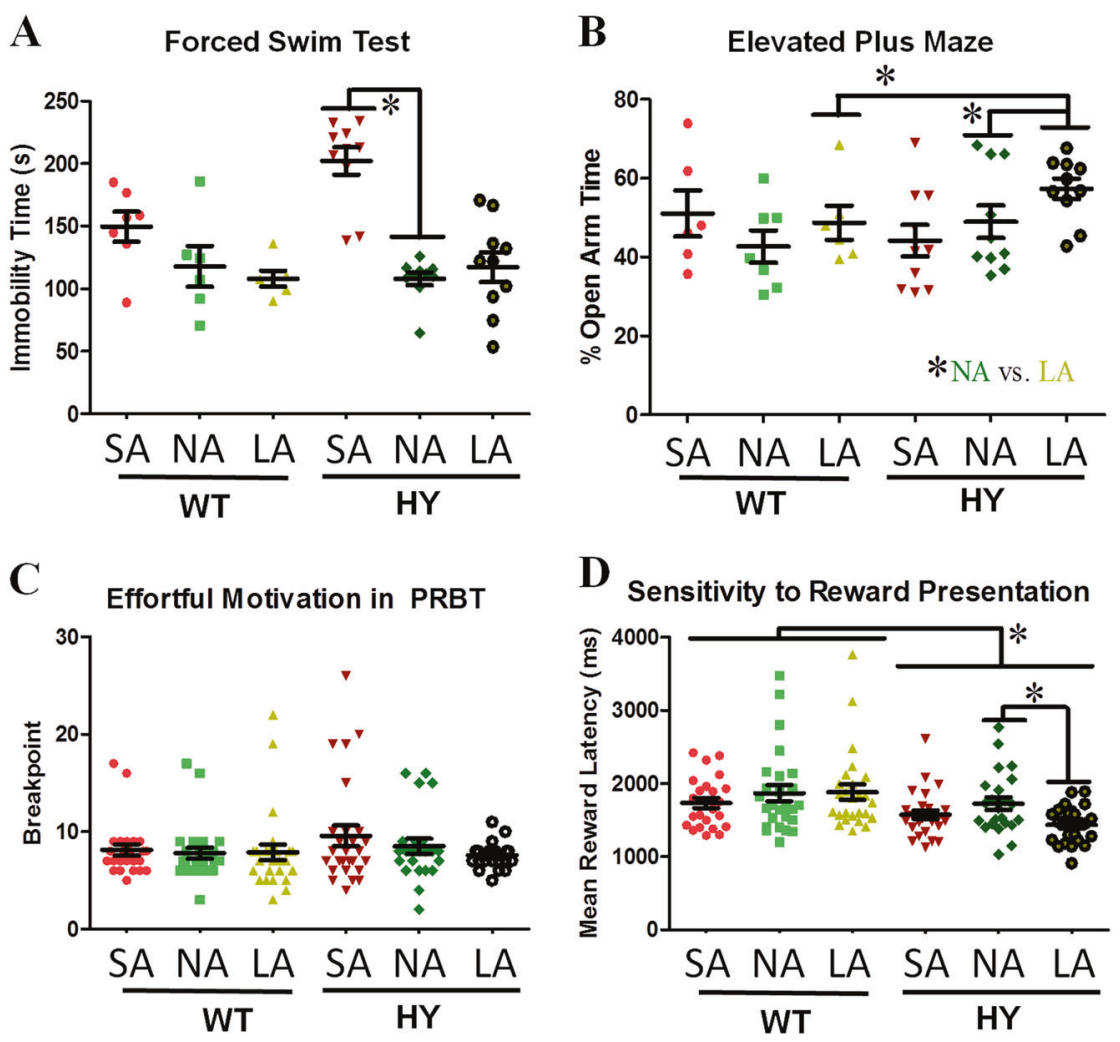

Fig. 2 Mice with reduced dopamine transporter (DAT) expression exhibit a hypersensitivity to the effects of winter-like and summer-like photoperiods effect on depression-relevant and mania-relevant behaviors. DAT hypomorphic (HY) and wildtype (WT) littermate mice exhibit increased depression-relevant behavior when housed in short-active (SA; 19L:5D) photoperiod conditions for 2 weeks, relative to controls (NA; 12 L:12D) as indicated by increased immobility (despair-like behavior), in the forced swim test (FST; a). This effect was greater in DAT HY compared with WT littermate mice. Mice housed in long-active (LA; 5 L:19D) photoperiod conditions for 2 weeks exhibit mania-like behavior as indicated by increased open arm entries (risk-prone behavior) in the elevated plus maze (EPM; b). Again this effect was exaggerated in DAT HY compared with WT littermate mice. Although neither photoperiod altered effortful motivation (breakpoint) as measured in the progressive ratio breakpoint test (PRBS; c), LA photoperiod condition increased reward sensitivity in DAT HY but not WT littermate mice as measured by a faster latency to collect rewards (d). Data presented as individual data points plus mean \pm S.E.M. Asterisk denotes $p<0.05$ as indicated

Quantification of CRH neurons

For quantification of hypothalamic $\mathrm{CRH}+$ neurons, $\mathrm{CRH}$-ires-Cre mice crossed with a floxed-tdTomato reporter line were exposed for 14 days to different photoperiods, then perfused and processed for IHC as described above. $\mathrm{CRH} / \mathrm{tdT}$ Tomato neurons were detected by confocal imaging and quantified with Photoshop CS counting tool.

\section{DAT RT-PCR}

DAT RNA expression levels across photoperiods were measured by quantitative RT-PCR. Mouse brains were dissected on ice. The hypothalamus was isolated and stored in $0.5 \mathrm{~mL}$ RNA-Later (Quiagen) at $-40^{\circ} \mathrm{C}$. After extraction (Quiagen RNAeasy mini-kit), total RNA was reverse transcribed by random decamer primer protocol (RETROscript kit, Ambion). Real-Time PCR analysis was conducted on a Light Cycler 480 system (Roche). Primers to detect $\mathrm{nAChR}$ trascripts were designed using the Roche online tool (Assay Design Center) and validated before use. Data were analyzed by comparative $\Delta_{\mathrm{CT}}$ method.

Statistical analyses

After confirming homogeneity of variance, primary outcome variables were analyzed using a targeted one-way or two-way analysis of variance (ANOVA) with photoperiod condition and genotype as between-subjects factors. Any significant main or interactive effects were subjected to further analyses using oneway ANOVAs and/or Tukey post hoc comparisons. Secondary outcome variables across tasks were subjected to a multi-variate
ANOVA with a Bonferroni-Sidak correction for multiple comparisons of any significant effect. All data were analyzed used SPSS 24.0 (Chicago, IL.) and represented by mean and standard error of the mean. Alpha level was set to 0.05 .

\section{RESULTS}

SA and LA photoperiod housing drives depression-like and risk taking-like behavior in mice respectively

Housing C57BL/6J mice in extreme photoperiod lengths changed behavior to depression-like or mania-like when compared with normal photoperiod lengths. Male C57BL/6J mice $(n=33)$ were housed in one of three photoperiod conditions, L:D 19:5, 12:12, or 5:19 to provide SA, NA, and LA photoperiods, respectively. After 2 weeks, mice were then tested in the EPM then the FST during their dark cycle. Photoperiod significantly affected immobility time in the FST $\left[F_{(2,30)}=14.2, p<0.0001\right.$; Fig. 1a]. Post hoc analyses revealed that mice in the $S A$ period exhibited higher immobility time compared with NA or LA period mice $(p<0.001)$. Photoperiod also affected EPM behavior of mice as measured by \%open arm entries $\left[F_{(2,30)}=18.8, p<0.001\right.$; Fig. $\left.1 \mathrm{~b}\right]$. Post hoc analyses revealed that mice kept in the LA period exhibited higher \% open arm entries compared with NA and SA period housed mice $(p<0.001)$.

SA and LA photoperiod exposure influences the number of $\mathrm{TH}$ expressing and SST-expressing neurons in the PVN of adult mice Brains of male $\mathrm{C} 57 \mathrm{BL} / 6 \mathrm{~J}$ mice $(N=33)$ were processed for $\mathrm{TH}+$ and SST+ IHC to measure changes in dopaminergic and SST 
expression across photoperiods. Quantification of immunoreactive neurons of the PVN showed that 14-day exposure to altered photoperiods significantly affected the number of $\mathrm{TH}+\left[F_{(2,15)}=\right.$ 24.6, $p<0.001$; Fig. $1 \mathrm{c}]$ and SST $+\left[F_{(2,12)}=4.3, p<0.05\right.$; Fig. 1d]. Dunnet's $t$-test post hocs (NA; 12L:12D as control) revealed a significant effect of SA increasing $(p<0.05)$ and LA reducing $(p<$ $0.01) \mathrm{TH}+$ neuron number. Dunnet's $t$-tests revealed a significant effect induced by SA increasing $(p<0.05)$ but LA not affecting ( $p$ $=0.74) \mathrm{SST}+$ neuron number. Tukey HSD demonstrated higher SST+ neurons in SA vs. LA photoperiod conditions $(p<0.05)$.
A

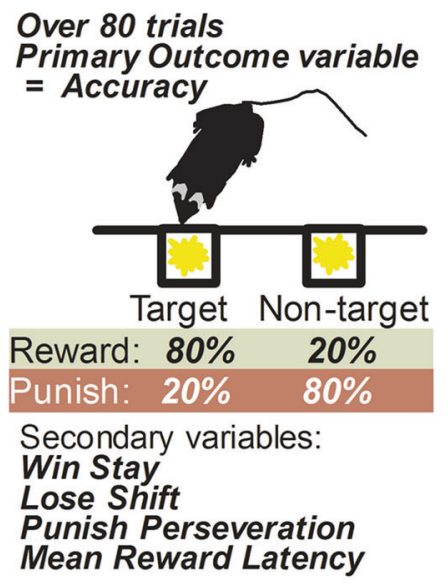

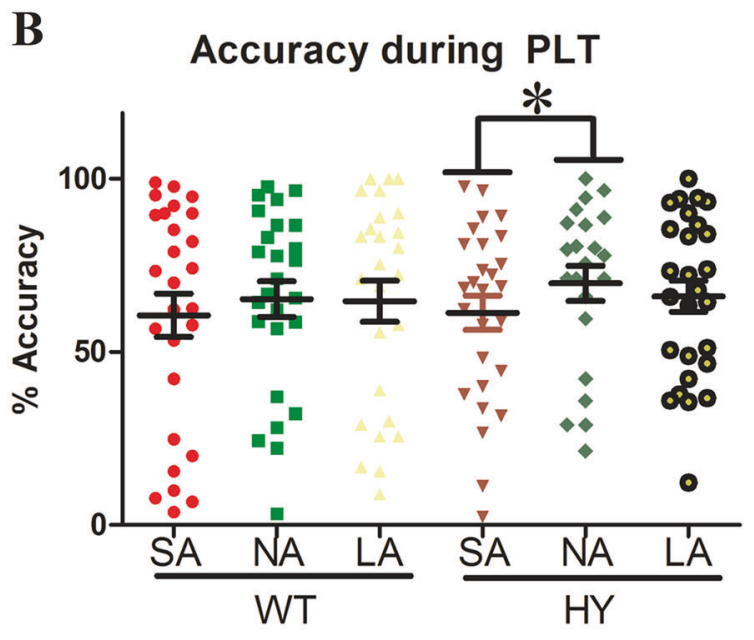

\section{Short Active-induced Punish Sensitivity Long Active-induced Reward Sensitivity Lose Shift Ratio in PLT Staying after Reward in PLT}
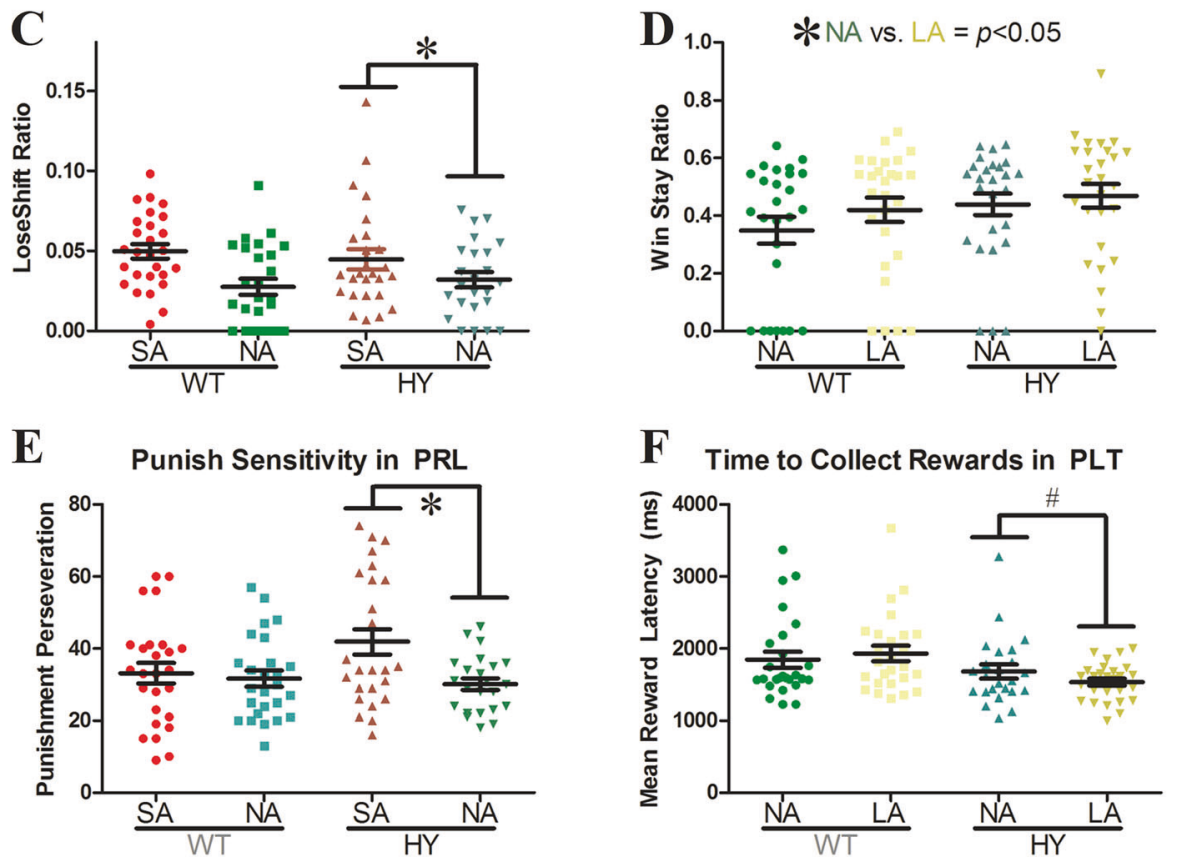

Fig. 3 Mice with reduced dopamine transporter (DAT) expression exhibit a hypersensitivity to the effects of winter-like and summer-like photoperiods effect on depression-relevant and mania-relevant behavior from the probabilistic learning task (PLT). The PLT assesses learning within a single session (a). Rodents select from two options (designated target and non-target) that provide reward (milkshake) and punishment (timeout) feedback based on an $80 / 20$ or 20/80 feedback ratio (respectively). Overall accuracy (target:non-target choices) can be measured. Importantly for mania-relevant and depression-relevant research however, reward-based (win-stay: repeating a choice after a reward, reward latency: time to collect a reward), and punishment-based (lose-shift: shifting choice after a punishment, punish perseveration: repeating responses during a punishment when all apertures are unresponsive), decision-making can also be quantified. DAT hypomorphic (HY) mice housed for 2 weeks in a short-active (SA; 19L:5D) photoperiod exhibited impaired accuracy compared with those housed in a normal-active (NA; 12 L:12D) photoperiod (b). Photoperiod condition did not affect wildtype (WT) littermate mice. The SA-induced deficits in accuracy in DAT-HY mice was likely a result of increased punish sensitivity behavior as measured by increased lose-shift (c), and punish perseveration (e) in these mice relative to NA-housed mice. Although long-active (LA; 5 L;19D) photoperiod lengths did not affect accuracy, mice housed in the LA photoperiod exhibited increased reward-sensitive behavior as measured by increased win-stay behavior irrespective of genotype (d), with DAT-HY mice again selectively exhibiting faster reward collection latencies (f), compared with the NA photoperiod condition. Data presented as individual data points plus mean \pm S.E.M. Asterisk denotes $p<0.05$ as indicated 

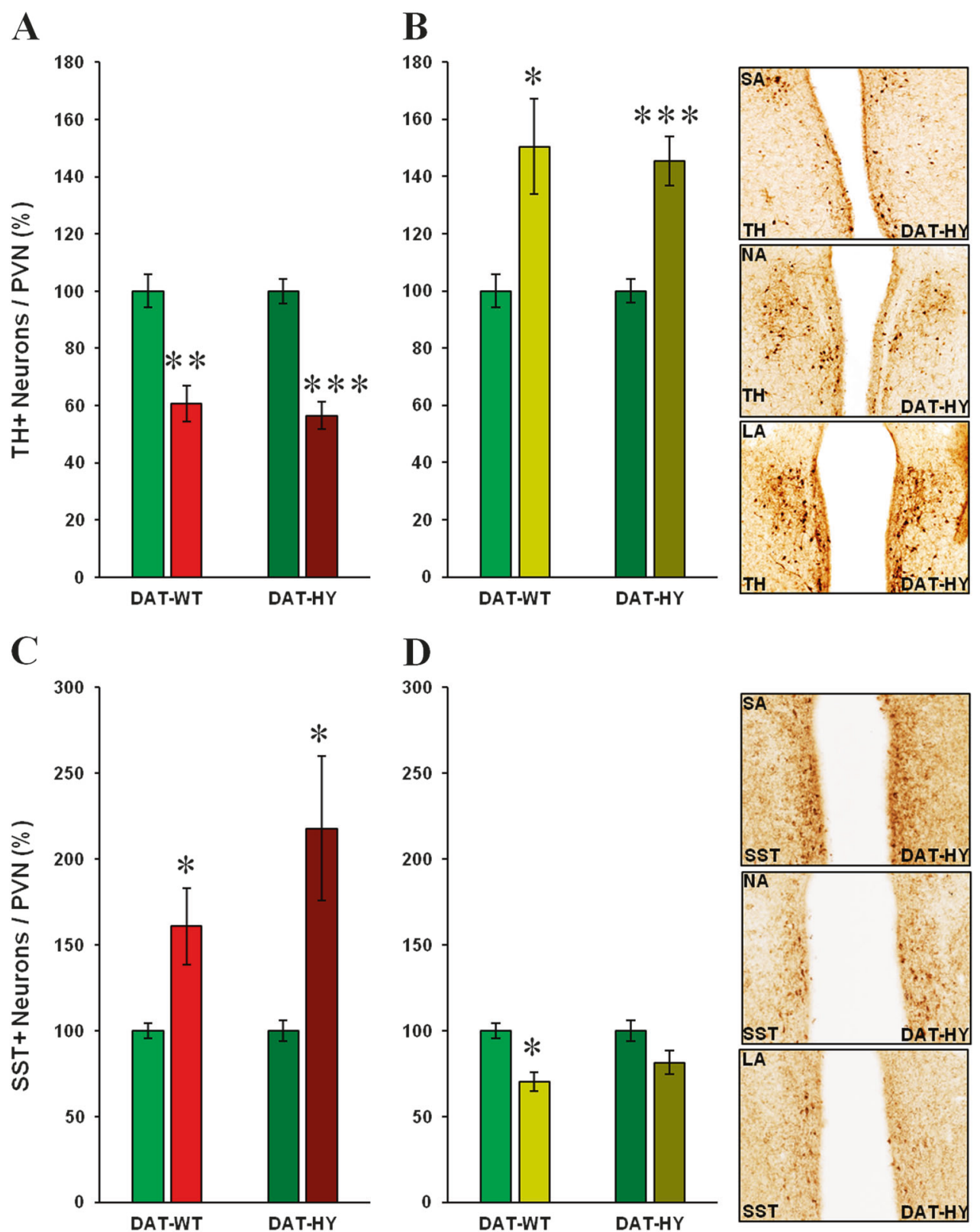

Fig. 4 Winter-like and summer-like photoperiods regulate the number of TH+ and SST+ neurons in the paraventricular nuclei (PVN) of mice with reduced dopamine transporter (DAT HY) and their wildtype (WT) littermates. Short-active (SA; 19 L;5D shown in red; a), and long-active (LA; 5 L;19D; shown in yellow; b) photoperiods differentially affected expression on the number of TH+ neurons in the PVN, irrespective of genotype compared with normal active (NA shown in green; 12:12) photoperiod exposure. SA photoperiod exposure reduced TH, while LA photoperiod exposure elevated TH expression. Similarly, SA (c) and LA (d) photoperiods also differentially affected the number of SST+ neurons, elevating and reducing numbers respectively, in both WT and HY mice. Representative images of TH and SST immunoreactivity within the PVN from each photoperiod condition in DAT HY mice are presented. Data presented as mean \pm S.E.M. ${ }^{*} p<0.05,{ }^{* *} p<0.01,{ }^{* * *} p<$ 0.001 compared with NA (normal active, 12 L:12D), photoperiod control

SA and LA photoperiod housing does not alter the number of $\mathrm{CRH}$ + in the PVN of adult mice

Brains of male $(N=6) \mathrm{CRH} / \mathrm{tdT}$ Tomato mice were processed for $\mathrm{TH}$ + and tdTomato fluorescent IHC to visualize dopaminergic and $\mathrm{CRH}$-expressing neurons in the hypothalamus. Quantification of immunoreactive neurons in the PVN revealed that extreme photoperiods exposure did not to affect the number of $\mathrm{CRH}+$ neurons $(F<1$, ns; see Supplemental Fig. 1).

SA conditions induced depression-like behaviors equally in CLOCK $\Delta 19$ and WT mice

Consistent with previous reports, Clock $\Delta 19$ mutant mice exhibited reduced immobility in the FST $\left[F_{(1,41)}=39.0, p<0.001\right.$ :
Supplemental Fig. 1], while consistent with results of Fig. 1, SA photoperiod induced increased immobility in mice in the FST irrespective of genotype $\left[F_{(1,41)}=4.1, p<0.05\right.$ : Supplemental Fig. 2].

SA and LA photoperiod housing drives depression-like and manialike behavior more in DAT HY than WT mice

Male DAT HY $(n=30)$ and WT $(n=19)$ mice were housed in one of the three photoperiod conditions (SA; 19:5, NA; 12:12, or LA; 5:19). After 14 days, these mice were tested in the EPM and the FST during their dark cycle. A significant interaction between photoperiod and genotype was observed $\left[F_{(2,43)}=4.3, p<0.05\right.$; Fig. 2a], whereby mice housed in the SA photoperiod exhibited 
increased immobility time irrespective of genotype. This effect was exaggerated in the HY (Cohen's $d=4.492$ ) compared with WT (Cohen's $d=0.912)$ mice $(p<0.05)$. Photoperiod and genotype also tended to interact with \%open arm entries $\left[F_{(2,43)}=3.9\right.$, $p=0.063$; Fig. 2b]. Here, mice in the LA photoperiod exhibited more \%open arm entries compared with the other two conditions $(p<0.05)$, an effect again exaggerated in HY (Cohen's $d=1.410)$ compared with WT (Cohen's $d=0.820)$ mice $(p<0.05)$.

LA photoperiods shift reward-sensitivity behavior in DAT-HY mice only, as assessed in the PRBS

During initial training, DAT HY mice acquired FR1 training (HAB2) faster than WT littermates $\left[F_{(1,68)}=6.7, p<0.001\right]$. After stability confirmation, WT $(n=76)$, and HY $(n=76)$, mice were counterbalanced into three groups and placed in altered photoperiods ( $n$ =23-26 per photoperiod). Mice were then tested in the PRBS. Photoperiod did not affect the effortful motivation (breakpoint) of mice. Despite elevated breakpoints observed in DAT-HY mice, this effect was not significant, nor was there a significant genotype $X$ photoperiod interaction ( $F<1$, ns; Fig. 2c). In contrast however, and consistent with the PLT (below), a main effect of genotype was observed on the latency to collect rewards, with DAT-HY mice collecting rewards faster than WT mice $\left[F_{(1,145)}=8.2, p<0.01\right.$; Fig. 2d]. Although no main effect nor interaction was observed with photoperiod, targeted analyses revealed that this speeding of reward collection of DAT-HY mice was observed only when housed in the LA photoperiod $\left[F_{(1,49)}=5.7, p<0.05\right]$, not in SA or NA conditions $(F<1, n s)$. Given that no speeding of choice latency occurred during LA photoperiods in DAT-HY vs. WT littermates, nor in any other condition $(F<1, \mathrm{~ns})$, the LA photoperiod-induced speeding of activity was only in response to collecting rewards. Hence, in two separate experiments LA photoperiods sped reward collection in DAT-HY mice, an effect not seen in WT mice.

SA and LA photoperiods shift punishment-sensitivity and rewardsensitivity behavior in DAT-HY mice only, as assessed in the probabilistic learning task (PLT)

PLT performance produces a variety of outcome measures relevant to reward-relevant and/or punishment-relevant behavior. As with the EPM and FST, specific predictions were made based on these measures, i.e., LA photoperiod condition would affect reward-related behaviors, while SA photoperiod condition would affect punishment-related behaviors. Hence, SA was compared with NA on punishment-relevant secondary measures, while LA was compared with NA on reward-relevant behaviors.

First, all animals performed all 80 trials, wherein one stimulus was designated the target, the other the non-target, with reward (milkshake) and punishments (time-out) occurring at a ratio of $80 /$ 20 and 20/80 respectively (see Fig. 3a). In terms of accuracy, overall SA photoperiod-housed mice exhibited poorer accuracy than NA-housed mice $\left[F_{(1,25)}=4.3, p<0.05\right.$; Fig. 3b]. This SAinduced deficit in accuracy appeared to be driven by DAT-HY rather than WT mice but no interaction was observed. The poor accuracy was likely driven by increased punish sensitivity as SAhoused mice exhibited higher lose-shift ratios $\left[F_{(1,25)}=9.3, p<\right.$ 0.01 ; Fig. $3 c]$, that tended toward a genotype $X$ photoperiod interaction $\left[F_{(1,25)}=2.3, p=0.09\right]$, with SA-housed HY mice exhibiting higher lose-shift ratios than their NA-housed littermates $\left[F_{(1,14)}=15.7, p<0.01\right]$, while no difference was seen in WT mice $(F<1, n s)$. Importantly, DAT HY mice also exhibited significantly higher perseverative behaviors during punishment when housed in the SA vs. NA condition $\left[F_{(1,14)}=5.8, p<0.05\right.$; Fig. 3d], an effect not seen in WT mice $(F<1$, ns), driven by a genotype $X$ photoperiod interaction trend $\left[F_{(1,99)}=3.3, p=0.072\right]$. Hence, SA photoperiod conditions appeared to worsen performance in DATHY mice driven by increased punish sensitivity relative to WT littermates.
In terms of mania-like behavior, specific NA vs. LA comparisons were conducted. No main effect of photoperiod or genotype, or their interaction was observed for accuracy. Interestingly however, a photoperiod effect was observed on non-target win-stay behavior $\left[F_{(1,25)}=4.3, p<0.05\right.$; Fig. 3e]. No genotype or genotype $X$ photoperiod interaction meant that on the rare times mice were rewarded in the non-target side, they were more likely to repeat their choice on that side, irrespective of genotype. In terms of when actual rewards were presented, a genotype $\mathrm{X}$ photoperiod effect was observed $\left[F_{(1,26)}=4.4, p<0.05\right]$. HY mice tended to collect rewards faster than WT mice overall $\left[F_{(1,64)}=3.1, p=0.081\right.$; Fig. 3f]. Importantly, when housed in a LA photoperiod condition, DAT HY tended to speed up their collection of the reward $(p<0.1)$, an effect not observed in WT mice.

\section{SA and LA photoperiod exposure affects TH and SST expression in DAT HY and DAT WT mice}

Brains of male DAT HY $(N=21)$ and WT mice $(N=11)$ were processed for $\mathrm{TH}+$ and SST+ IHC. Immunoreactive neurons were quantified in the hypothalamic PVN. Two-way ANOVA revealed a significant main effect of both $\mathrm{SA}\left[F_{(1,25)}=58.9, p<0.001\right.$; Fig. 4a] and LA $\left[F_{(1,25)}=22.3, p<0.001\right.$; Fig. 4b] photoperiods on the number of $\mathrm{TH}+$ neurons, but no main effect of genotype and no interaction. Similarly, but in an inverse function, a significant main effect of both SA $\left[F_{(1,22)}=9.7, p<0.01\right.$; Fig. $\left.4 c\right]$ and $\mathrm{LA}\left[F_{(1,20)}=17.7, p<0.001\right.$; Fig. $\left.4 \mathrm{~d}\right]$ photoperiods on SST + neuron number was observed, but no main effect of genotype and no interaction.

\section{DAT mRNA levels in the hypothalamus of DAT HY mice are unaffected by SA and LA photoperiod housing}

Brains of male DAT HY $(N=9)$ and DAT WT mice $(N=9)$ were processed for DAT mRNA quantification by RT-PCR (Fig. 5). Twoway ANOVA showed a significant main effect of photoperiod $\left[F_{(2,10)}=4.8, \quad p<0.05\right]$ and a significant interaction between photoperiod and genotype $\left[F_{(2,10)}=4.2, p<0.05\right.$; Fig. 5a]. DAT mRNA levels follow TH expression in WT mice but seem not to be affected by photoperiod in DAT-HY mice. Fold changes in mRNA amount are relative to the NA WT condition. DAT mRNA levels also appear to be enriched compared to the baseline displayed by WT littermates exposed to control condition (12L:12D), which could be a compensatory effect due to the reduced translation of DAT protein and its trafficking to the cell membrane in this mutant. In other words, the increased baseline of RNA in HY mice could be the result of an altered system generating excess of DAT transcript but not getting the expected functional DA transport.

\section{DISCUSSION}

Photoperiod length switches drive mania- and depressionrelevant behaviors across species given that mice were similarly affected to rats [26]. Long-active (LA) photoperiods resulted in mice exhibiting risk-preferring behavior, measured by elevated open arm entries. Importantly, mice with reduced DAT expression exhibited a hypersensitivity to this LA photoperiod-induced risk preference. In the opposite fashion-and consistent with BDDAT HY mice exhibited a hypersensitivity to SA photoperiodinduced depression-relevant behaviors (elevated immobility in the FST) in mice. Interestingly, although seasonal photoperiod variation affected Clock $\Delta 19$ mice, they were not hypersensitive to the effects. All mice exhibited shifts in IHC signatures of TH and SST, consistent with rat studies [26]. Most importantly, when tested in psychiatry-relevant tasks such as the PLT and PRBS, DAT-HY mice exhibited reward hypersensitivity when in LA photoperiod conditions, but punish hypersensitivity when in SA photoperiod conditions (Table 1). These findings are consistent with seasonal variation in mood seen in $\mathrm{BD}$ patients $([7,8,10]$; 

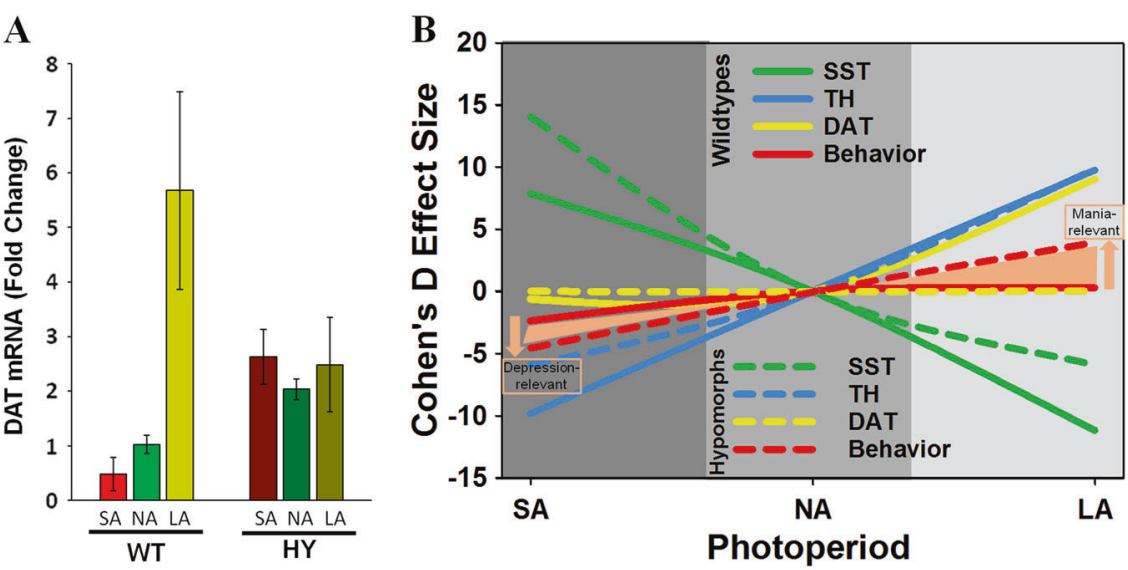

Fig. 5 Altered photoperiod does not affect dopamine transporter (DAT) mRNA levels in the hypothalamus of DAT-Hypomorphic (HY) mice, hence the hypersensitivity of DAT-HY mice to altering photoperiod may arise from lack of homeostatic control. Altering photoperiod lengths affected DAT mRNA levels in wildtype (WT), but not DAT-HY mice (a). Average effect sizes for immunohistochemical and depression-relevant and mania-relevant behaviors were calculated for WT and DAT HY mice in each photoperiod (short-active; SA vs. long-active; LA) relative to NA controls. Hence, WT mice exhibited significant but modest changes in behavior (red line), tyrosine hydroxylase (TH; blue line), and somatostatin (SST; green line) expression as a result of changing photoperiods, with DAT mRNA (yellow line) changing to maintain homeostatic control (b). In contrast, DAT HY mice exhibited similar changes in TH and SST expression but stronger changes in behavior, likely as a result of inability to exert DAT homeostatic control (b). The increased effect sizes of photoperiod on behavior in DAT HY vs. WT mice are indicated in orange, with depression-relevant behaviors during SA, and mania-relevant behaviors during LA photoperiods

\begin{tabular}{|c|c|c|c|c|c|c|}
\hline \multirow[t]{2}{*}{$\begin{array}{l}\text { Behavioral } \\
\text { domain }\end{array}$} & \multirow[t]{2}{*}{ Dependant measure } & $\begin{array}{l}\text { DAT- } \\
\text { WT }\end{array}$ & \multicolumn{2}{|c|}{$\begin{array}{l}\text { DAT- } \\
\text { HT }\end{array}$} & \multicolumn{2}{|c|}{ Clock $\Delta 19$} \\
\hline & & SA LA & SA & LA $S$ & SA & LA \\
\hline $\begin{array}{l}\text { epression- } \\
\text { levant }\end{array}$ & FST & $\uparrow \quad-$ & $\uparrow \uparrow$ & - & $\downarrow$ m.e. & $\downarrow \mathrm{m} . \mathrm{e}$ \\
\hline ania-relevant & $\begin{array}{l}\text { EPM Open arm } \\
\text { entries }\end{array}$ & $-\uparrow$ & - & $\uparrow \uparrow r$ & n.a. & n.a. \\
\hline Reward learning & PLT Accuracy & $-\quad-$ & $\downarrow \downarrow-$ & $-r$ & n.a. & n.a. \\
\hline \multirow[t]{2}{*}{$\begin{array}{l}\text { Punish } \\
\text { sensitivity }\end{array}$} & $\begin{array}{l}\text { PLT Timeout } \\
\text { perseveration }\end{array}$ & - & $\uparrow \uparrow-$ & $-r$ & n.a. & n.a. \\
\hline & PLT Target lose shift & - & $\uparrow \uparrow-$ & - & n.a. & n.a. \\
\hline $\begin{array}{l}\text { Reward } \\
\text { sensitivity }\end{array}$ & $\begin{array}{l}\text { Reward collection } \\
\text { latency }\end{array}$ & - & - & $\downarrow \downarrow r$ & n.a. & n.a. \\
\hline \multicolumn{7}{|c|}{$\begin{array}{l}\text { Summary of effects in BD-relevant behavioral domains vs. respective NA } \\
\text { photoperiod. Main effect only vs. wildtype denoted by m.e. Direction of } \\
\text { effect for respective dependent measure is reflected by arrow direction. } \\
\text { Dashes represent no effect. Single arrows indicate significant effect of } \\
\text { photoperiod relative to NA photoperiods within genotype (WT includes } \\
\text { C57BL/6 findings). Double arrows indicate main effects driven by effect } \\
\text { seen only in mutant mice not in WTs of that cohort-representative of } \\
\text { hypersensitivity in the respective behavior to photoperiod. Domains not } \\
\text { assessed are denoted n.a. } \\
\text { FST Forced swim test, despair-relevant, EPM elevated plus maze, risk-taking- } \\
\text { relevant, PLT probabilistic learning task }\end{array}$} \\
\hline
\end{tabular}

Parker et al., 1982; [11, 12]; Volpe et al., 2006; Wang et al., 2013), with mania associated reward hypersensitivity in LA photoperiods, but depression and punish hypersensitivity in SA photoperiods.

Identifying the mechanism underlying the switch between states in BD has been noted as the "holy grail" of BD research. Several theories have been postulated including the kindling hypothesis [47], although it may be relevant to several diseases limiting its specificity to BD ([48]; Young et al, 2015). Given seasonal-induced switching between states has been reported in 23 of 29 BD studies (Wang et al, 2013), this mechanism is likely specific and fundamental to BD. Neurons of the hypothalamic PVN switch between two neurotransmitter states dependent upon photoperiod length across species in rats [26], and now mice, likely represent a component of that undiscovered mechanism. The duration of altered photoperiod exposure required to induce NT plasticity was doubled in mice (2 weeks) compared to rats (1 week) possibly due to the genetic variation of melatonin expression in laboratory mice under domestication [49]. It is clear however, that this seasonal-induced neurotransmitter switching alone did not produce large effect size changes in behavior in normal rodents, unlike the extremes of $\mathrm{BD}$, indicative that such cellular and biochemical changes precede some of the BD-like behavioral phenotypes (Fig. 5b). Quantifiable prodromal symptoms and decompensation may precede a full relapse episode in BD sufferers by as much as 4 weeks $[50,51]$. Extended exposure to shifted photoperiod may further exacerbate phenotypes in DATHY mice resulting here from only 2 weeks exposure. The inability of DAT-HY mice to modulate DAT expression to changing photoperiod lengths may contribute to switching between states in BD (Fig. 5b). The data provided here point toward the beginning of delineating molecular mechanism(s) between states in $\mathrm{BD}$ that could potentially provide new circuits to target before manifestation of extreme BD states.

The data produced here utilized ethologically- and psychiatryrelevant behaviors as well as molecular characterization of neurotransmitter plasticity in identified neurons of the adult brain to delineate SA photoperiods driving depression-relevant behaviors. Consistent with rats [26], mice kept in SA photoperiod conditions exhibited depression-like behavior as indicated by increased immobility in the FST. These findings contrast with an earlier study in C57BL/6 mice that used a 3-week photoperiod length before testing in FST [52] This change could be due to lower sample sizes, or due to their testing during both inactive (light) and active (dark) photoperiods. In contrast, we observed reproducible SA-induced increased in immobility across three studies, demonstrating reproducibility of this main finding. When directly comparable cross-species tasks were utilized-those used in clinical populations-SA photoperiod drove a hypersensitivity to punishment in the PLT-increased perseverations and shiftsensitivity during punishment-an effect specific to DAT-HY, not WT mice. Such punish-sensitivity is a hallmark feature of human depression [53, 54]. Furthermore, SA photoperiod impaired 
accuracy of DAT-HY but not WT mice. This SA photoperiod condition also increased SST and reduced TH expression in both groups. Given the altered $\mathrm{TH}+/ \mathrm{TH}-$ expression changes seen in humans that died in summer vs. winter [27], these findings provide clear behavioral and neurochemical relationship to human observations. The number of CRF + cells, which are the target neurons receiving inhibitory modulation from the presynaptic dopaminergic neurons [26], was unchanged across photoperiods, however the observed changes in stress responses (EPM and FST) are likely due to the inhibitory effect of dopamine receptors expressed on $\mathrm{CRH}+$ target cells. Interestingly, WT mice exhibit reduced DAT mRNA expression when kept in a SA photoperiod condition, while DAT-HY mice remain unchanged. It is clear that when mice are kept in a SA photoperiod, they exhibit depression-relevant behaviors, an effect exaggerated in mice with reduced DAT expression likely driven by an inability to homeostatically respond. In other words, reduced trafficking of the DAT protein to the cell membrane in DAT-HY mice might further contribute to the hypersensitivity observed in these mice in SA photoperiod when active uptake of reduced dopamine from the synaptic cleft is crucial.

Behaviors specific to mania differ markedly from those of depression, with increased risk-preference and reward sensitivity seen during mania [55]. Mice housed in LA (summer-like) photoperiod conditions exhibited risk-preferring behaviors, as measured by increased open arm entries in the EPM [56]. Surprisingly, when LA-photoperiod mice were tested in the PRBS, they did not exhibit increased motivation (breakpoint) for the same reward. They did however speed their movement to collect rewards when presented. This same reward-sensitivity was observed in the PLT, without affecting choice latencies, indicating a selective effect on reward-related event processing. This change in response sensitivity during LA photoperiod was accompanied by elevated PVN TH levels, similar to elevated TH in the midbrain of healthy humans that died in summer [27]. Importantly, LA photoperiods induced reward sensitivity in mice, particularly in DAT-HY and not WT mice.

Although an altered behavioral profile of Clock $\Delta 19$ mice were observed when tested during their sleep cycle [33, 34], they are also more active in their wake-cycle and did not exhibit a manialike profile in the BPM [39]. Photoperiodic plasticity in the hypothalamic expression of other genes implicated in light perception occur. The rapid switching of hypothalamic gene expression (including eya3, tsh beta, dio2, pax6 and rhodopsin, with decreased dio 3 mRNA at 13 and $16 \mathrm{~h}$ but not 8 or 11 post exposure), potentially underlies photoperiod-induced seasonal plasticity [57]. Alterations of any of these genes may provide further sensitivity -or resiliency- to the effects of photoperiod seasonal switching on behavior. Of specific interest to BD is the observation that a genome-wide association study identified an association for rs41350144, which lies within an intron of NF1A gene on $1 \mathrm{p} 31$, predisposing seasonal pattern of $\mathrm{BD}$ [58]. A more targeted approach examining circadian genes related to seasonality identified 5 SNPs in NPAS2 and CRY2 [59]. These genes were associated with seasonality irrespective of gender. Although we did not assess sex-effects here, our preliminary data indicated consistent effects across sexes (data not shown). Given that seasonality in BD is observed across genders, with little sex-effects in DAT mutant mice, we would expect similar findings in female mice. Combining sex effect analysis in additional genetic susceptibilities to photoperiod-induced changes in behavior will be vital in future research in BD.

Despite these studies demonstrating for what appears to be the first potential molecular and cellular mechanism underlying switching between states in $\mathrm{BD}$, limitations exist. The sample sizes used in the present studies were sufficient for main effects, but genotype by photoperiod interactive effects were not always observed. Powering for the potential main effect of sex or interactions on such trained behaviors may require even larger sample sizes. In addition, investigating the neurotransmitter plasticity, if any, induced by changing photoperiods beyond the PVN would be useful, such as confirmation of seasonal midbrain $\mathrm{TH}$ changes as seen in humans [27]. Future studies could utilize diurnal rodents for greater light-level consistency compared with humans, e.g., in the diurnal grass rat [60], although genetic manipulations are not as readily available in these species. Finally, as identified not every BD sufferer experiences seasonalinduced switching and so this mechanism may only be specific to such seasonal BD sufferers $([7,8,10]$; Parker et al, 1982; [11, 12]; Volpe et al, 2006). The underlying circuitry of each state is likely to be similar however, and so these factors may be useful toward delineating neural mechanisms underlying $\mathrm{BD}$ as a whole.

In summary, as demonstrated by effect size comparisons in Fig. $5 \mathrm{~b}$, we provide behavioral data describing switching between extreme behavioral states in a novel behavioral mouse model of $\mathrm{BD}$ (Young et al, 2015) - not solely of mania or depression. Winterlike (SA) photoperiods induced depression-relevant punish sensitivity in DAT-HY mice, while long-active (summer-like) photoperiods induced mania-relevant reward sensitivity in DATHY mice. Although this platform of assessment has investigated only the role of reduced DAT functioning in response to changing seasons, it can be used to further assess genetic sensitivity and potential mechanisms conferring sensitivity and/or resilience and the neural states during each state, e.g., catecholaminergic during mania or acetylcholinergic during depression [6]. Now that photoperiod-dependent neurotransmitter plasticity affecting behavior has been established in mice, the availability of transgenic mice carrying specific gene mutations associated with $\mathrm{BD}$ and state-of-the-art tools designed to investigate the effect of gene manipulations in vivo will enable investigating BD state switching mechanism with great sophistication at the circuit level.

\section{ACKNOWLEDGEMENTS}

The authors thank Drs. Mark Geyer, William Perry, Nicholas Spitzer, and Arpi Minassian, as well as Ms. Mahalah Buell for their invaluable support. They would also like to thank their Advisory Board.

\section{FUNDING}

These studies were made possible by funding from NIMH grant R01MH104344-03, T32MH018399-30, and the Veteran's Administration VISN 22 Mental Illness Research, Education, and Clinical Center, as well as by the Kavli Institute for Brain and Mind (KIBM) grant (2016-038) awarded to Davide Dulcis.

\section{ADDITIONAL INFORMATION}

Supplementary information accompanies this paper at https://doi.org/10.1038/ s41386-018-0031-y.

Conflict of interest: The authors declare that they have no conflict of interest.

Publisher's note: Springer Nature remains neutral with regard to jurisdictional claims in published maps and institutional affiliations.

\section{REFERENCES}

1. Begley CE, Annegers JF, Swann AC, Lewis C, Coan S, Schnapp WB. et al. The lifetime cost of bipolar disorder in the US: an estimate for new cases in 1998 Pharmacoeconomics. 2001;19(5):483-95.

2. Blumberg HP. Euthymia, depression, and mania: what do we know about the switch? Biol Psychiatry. 2012;71:570-1.

3. van Enkhuizen J, Acheson D, Risbrough V, Drummond S, Geyer MA, Young JW. Sleep deprivation impairs performance in the 5-choice continuous performance test: similarities between humans and mice. Behav Brain Res. 2014;261: $40-8$. 
4. Young JW, Dulcis D. Investigating the mechanism(s) underlying switching between states in bipolar disorder. Eur J Pharmacol. 2015;759:151-62.

5. Gould TD, Einat H. Animal models of bipolar disorder and mood stabilizer efficacy: a critical need for improvement. Neurosci Biobehav Rev. 2007;31:825-31.

6. van Enkhuizen J, Janowsky DS, Olivier B, Minassian A, Perry W, Young JW, et al. The catecholaminergic-cholinergic balance hypothesis of bipolar disorder revisited. Eur J Pharmacol. 2015;753:114-26.

7. Lee HC, Tsai SY, Lin HC. Seasonal variations in bipolar disorder admissions and the association with climate: a population-based study. J Affect Disord. 2007;97:61-69.

8. Mulder RT, Cosgriff JP, Smith AM, Joyce PR. Seasonality of mania in New Zealand. Aust N Z J Psychiatry. 1990;24:187-90.

9. Parker $G$, Walter $S$. Seasonal variation in depressive disorders and suicidal deaths in New South Wales. Br J Psychiatry. 1982;140:626-32.

10. Barbini B, Di Molfetta D, Gasperini M, Manfredonia M, Smeraldi E. Seasonal concordance of recurrence in mood disorder patients. Eur Psychiatry. 1995;10:171-4.

11. Sayer HK, Marshall S, Mellsop GW. Mania and seasonality in the southern hemisphere. J Affect Disord. 1991;23:151-6.

12. Takei N, O'Callaghan E, Sham P, Glover G, Tamura A, Murray R. Seasonality of admissions in the psychoses: effect of diagnosis, sex, and age at onset. $\mathrm{Br} J$ Psychiatry. 1992;161:506-11.

13. Volpe FM, Del Porto JA. Seasonality of admissions for mania in a psychiatric hospital of Belo Horizonte, Brazil. J Affect Disord. 2006;94:243-8.

14. Wang B, Chen D. Evidence for seasonal mania: a review. J Psychiatr Pract. 2013;19:301-8.

15. Sherman JA. Evolutionary origin of bipolar disorder-revised: EOBD-R. Med Hypotheses. 2012;78:113-22.

16. Jacobsen FM, Wehr TA, Skwerer RA, Sack DA, Rosenthal NE. Morning versus midday phototherapy of seasonal affective disorder. Am J Psychiatry. 1987;144:1301-5.

17. Knapen SE, van de Werken M, Gordijn MC, Meesters Y. The duration of light treatment and therapy outcome in seasonal affective disorder. J Affect Disord. 2014;166:343-6.

18. Rosenthal NE, Sack DA, Gillin JC, Lewy AJ, Goodwin FK, Davenport Y, et al. Seasonal affective disorder. A description of the syndrome and preliminary findings with light therapy. Arch Gen Psychiatry. 1984;41:72-80.

19. Lam RW, Levitt AJ, Levitan RD, Michalak EE, Cheung AH, Morehouse R, et al. Efficacy of bright light treatment, fluoxetine, and the combination in patients with nonseasonal major depressive disorder: a randomized clinical trial. JAMA Psychiatry. 2016;73:56-63.

20. Postolache $\Pi$, Oren DA. Circadian phase shifting, alerting, and antidepressant effects of bright light treatment. Clin Sports Med. 2005;24:381-413.

21. Sit $\mathrm{D}$, Wisner $\mathrm{KL}$, Hanusa $\mathrm{BH}$, Stull S, Terman M. Light therapy for bipolar disorder: a case series in women. Bipolar Disord. 2007;9:918-27.

22. Wu JC, Kelsoe JR, Schachat C, Bunney BG, DeModena A, Golshan S, et al. Rapid and sustained antidepressant response with sleep deprivation and chronotherapy in bipolar disorder. Biol Psychiatry. 2009;66:298-301.

23. Grandin LD, Alloy LB, Abramson LY. The social zeitgeber theory, circadian rhythms, and mood disorders: review and evaluation. Clin Psychol Rev. 2006;26:679-94.

24. Malkoff-Schwartz S, Frank E, Anderson BP, Hlastala SA, Luther JF, Sherrill JT, et al. Social rhythm disruption and stressful life events in the onset of bipolar and unipolar episodes. Psychol Med. 2000;30:1005-16.

25. Dulcis D, Spitzer NC. Illumination controls differentiation of dopamine neurons regulating behaviour. Nature. 2008;456:195-201.

26. Dulcis $D$, Jamshidi $P$, Leutgeb $S$, Spitzer NC. Neurotransmitter switching in the adult brain regulates behavior. Science. 2013;340:449-53.

27. Aumann TD, Raabus M, Tomas D, Prijanto A, Churilov L, Spitzer NC, et al. Differences in number of midbrain dopamine neurons associated with summer and winter photoperiods in humans. PLoS One. 2016;11:e0158847.

28. McGuffin P, Rijsdijk F, Andrew M, Sham P, Katz R, Cardno A. The heritability of bipolar affective disorder and the genetic relationship to unipolar depression. Arch Gen Psychiatry. 2003;60:497-502.

29. Greenwood TA, Alexander M, Keck PE, McElroy S, Sadovnick AD, Remick RA, et al. Evidence for linkage disequilibrium between the dopamine transporter and bipolar disorder. Am J Med Genet. 2001;105:145-51.

30. Greenwood TA, Schork NJ, Eskin E, Kelsoe JR. Identification of additional variants within the human dopamine transporter gene provides further evidence for an association with bipolar disorder in two independent samples. Mol Psychiatry. 2006;11:125-33. 115

31. Horschitz $S$, Hummerich R, Lau T, Rietschel M, Schloss P. A dopamine transporter mutation associated with bipolar affective disorder causes inhibition of transporter cell surface expression. Mol Psychiatry. 2005;10:1104-9.
32. Anand A, Barkay G, Dzemidzic M, Albrecht D, Karne H, Zheng QH, et al. Striatal dopamine transporter availability in unmedicated bipolar disorder. Bipolar Disord. 2011;13:406-13.

33. McClung CA, Sidiropoulou K, Vitaterna M, Takahashi JS, White FJ, Cooper DC, et al. Regulation of dopaminergic transmission and cocaine reward by the Clock gene. Proc Natl Acad Sci USA. 2005;102:9377-81.

34. Roybal K, Theobold D, Graham A, DiNieri JA, Russo SJ, Krishnan V, et al. Mania-like behavior induced by disruption of CLOCK. Proc Natl Acad Sci USA. 2007;104:6406-11.

35. Landgraf D, Joiner WJ, McCarthy MJ, Kiessling S, Barandas R, Young JW, et al. The mood stabilizer valproic acid opposes the effects of dopamine on circadian rhythms. Neuropharmacology. 2016;107:262-70.

36. Zhuang X, Oosting RS, Jones SR, Gainetdinov RR, Miller GW, Caron MG, et al. Hyperactivity and impaired response habituation in hyperdopaminergic mice. Proc Natl Acad Sci USA. 2001;98:1982-7.

37. van Enkhuizen J, Geyer MA, Kooistra K, Young JW. Chronic valproate attenuates some, but not all, facets of mania-like behaviour in mice. Int J Neuropsychopharmacol. 2013a;16:1021-31.

38. van Enkhuizen J, Geyer MA, Young JW. Differential effects of dopamine transporter inhibitors in the rodent lowa gambling task: relevance to mania. Psychopharmacol (Berl). 2013b;225:661-74.

39. van Enkhuizen J, Minassian A, Young JW. Further evidence for ClockDelta19 mice as a model for bipolar disorder mania using cross-species tests of exploration and sensorimotor gating. Behav Brain Res. 2013c;249:44-54.

40. Cope ZA, Young JW. The five-choice continuous performance task (5c-cpt): a cross-species relevant paradigm for assessment of vigilance and response inhibition in rodents. Curr Protoc Neurosci. 2017;78:9 56 51-59 5618.

41. Young JW, Finlayson K, Spratt C, Marston HM, Crawford N, Kelly JS, et al. Nicotine improves sustained attention in mice: evidence for involvement of the alpha7 nicotinic acetylcholine receptor. Neuropsychopharmacology. 2004;29: 891-900.

42. Young JW, Light GA, Marston HM, Sharp R, Geyer MA. The 5-choice continuous performance test: evidence for a translational test of vigilance for mice. PLoS One. 2009;4:e4227.

43. Barnes SA, Young JW, Neill JC. D(1) receptor activation improves vigilance in rats as measured by the 5 -choice continuous performance test. Psychopharmacol (Berl). 2012a;220:129-41.

44. Barnes SA, Young JW, Neill JC. Rats tested after a washout period from subchronic PCP administration exhibited impaired performance in the 5-Choice Continuous Performance Test (5C-CPT) when the attentional load was increased. Neuropharmacology. 2012b;62:1432-41.

45. Young JW, Geyer MA. Action of modafinil--increased motivation via the dopamine transporter inhibition and D1 receptors? Biol Psychiatry. 2010;67:784-7.

46. Bensadoun JC, Brooks SP, Dunnett SB. Free operant and discrete trial performance of mice in the nine-hole box apparatus: validation using amphetamine and scopolamine. Psychopharmacol (Berl). 2004;174:396-405.

47. Post RM, Uhde TW, Putnam FW, Ballenger JC, Berrettini WH. Kindling and carbamazepine in affective illness. J Nerv Ment Dis. 1982;170:717-31.

48. Bender RE, Alloy LB. Life stress and kindling in bipolar disorder: review of the evidence and integration with emerging biopsychosocial theories. Clin Psychol Rev. 2011:31:383-98.

49. Kasahara T, Abe K, Mekada K, Yoshiki A, Kato T. Genetic variation of melatonin productivity in laboratory mice under domestication. Proc Natl Acad Sci USA. 2010;107:6412-7.

50. Keller MB, Lavori PW, Kane JM, Gelenberg AJ, Rosenbaum JF, Walzer EA, et al. Subsyndromal symptoms in bipolar disorder. A comparison of standard and low serum levels of lithium. Arch Gen Psychiatry. 1992:49:371-6.

51. Molnar G, Feeney MG, Fava GA. Duration and symptoms of bipolar prodromes. Am J Psychiatry. 1988;145:1576-8.

52. Flaisher-Grinberg S, Gampetro DR, Kronfeld-Schor N, Einat H. Inconsistent effects of photoperiod manipulations in tests for affective-like changes in mice: implications for the selection of appropriate model animals. Behav Pharmacol. 2011;22:23-30

53. Adida M, Jollant F, Clark L, Besnier N, Guillaume S, Kaladjian A, et al. Trait-related decision-making impairment in the three phases of bipolar disorder. Biol Psychiatry. 2011;70:357-65.

54. Must A, Horvath S, Nemeth VL, Janka Z. The lowa Gambling Task in depression-what have we learned about sub-optimal decision-making strategies? Front Psychol. 2013;4:732.

55. Cassidy F, Murry E, Forest K, Carroll BJ. Signs and symptoms of mania in pure and mixed episodes. J Affect Disord. 1998;50:187-201.

56. Pellow S, Chopin P, File SE, Briley M. Validation of open:closed arm entries in an elevated plus-maze as a measure of anxiety in the rat. J Neurosci Methods. 1985;14:149-67. 
Switching mechanisms in bipolar disorder...

JW Young et al.

57. Majumdar G, Rani S, Kumar V. Hypothalamic gene switches control transitions between seasonal life history states in a night-migratory photoperiodic songbird. Mol Cell Endocrinol. 2015;399:110-21.

58. Lee HJ, Woo HG, Greenwood TA, Kripke DF, Kelsoe JR. A genome-wide association study of seasonal pattern mania identifies NF1A as a possible susceptibility gene for bipolar disorder. J Affect Disord. 2013;145:200-7.
59. Geoffroy PA, Lajnef M, Bellivier F, Jamain S, Gard S, Kahn JP, et al. Genetic association study of circadian genes with seasonal pattern in bipolar disorders. Sci Rep. 2015;5:10232.

60. Leach G, Adidharma W, Yan L. Depression-like responses induced by daytime light deficiency in the diurnal grass rat (Arvicanthis niloticus). PLoS One. 2013;8: e57115. 